\title{
O TESTEMUNHO EM O SOBREVIVENTE: MEMÓRIA DE UM INFANTE QUE ESCAPOU DE AUSCHWITZ
}

Resumo: Apresentamos neste texto uma análise da obra O Sobrevivente: memórias de um brasileiro que escapou de Auschwitz, publicado em 2000, numa parceria entre Aleksander Laks e Tova Sender. Trata do testemunho de Laks enquanto menino judeupolonês, que experimentou na adolescência os traumas do cotidiano do campo de concentração de Auschwitz. A sobrevivência e sua relação de gratidão com o Brasil e sua identificação como brasileiro. Sua narrativa testemunha uma das maiores barbaridades sofridas por seu povo, durante a Shoah, na Segunda Guerra Mundial. Procuramos verificar de que forma a exceção e a vida nua se apresentam e dialogam na narrativa reverberando sua sobrevivência. $O$ nazismo sem dúvida nos lembra a tortura $e$ o sofrimento de um povo que foi penalizado, pois Auschwitz, não era apenas um campo de concentração, era também um campo de trabalho forçado, de humilhação, de sofrimento e de extermínio. Nessa perspectiva utilizaremos como chave de leitura as ideias de Giorgio Agamben baseado no estado de Exceção e na vida nua, conceitos estes considerados importantes para a compreensão e reflexão de um período em que os direitos fundamentais foram suspensos e a sua memória será sempre um desafio, principalmente quando se trata dos infantes.

Palavras chave: Testemunho. Exceção. Memória. Vida nua.
Rosane Castro PINTO ${ }^{1}$

Augusto SARMENTO-PANTOJA ${ }^{2}$

Universidade Federal do Pará (UFPA)

Abstract: We present in this text an analysis of the work O Sobrevivente: memórias de um brasileiro que escapou de Auschwitz, published in 2000, in a partnership between Aleksander Laks and Tova Sender. It deals with the testimony of Laks as a PolishJewish boy, who experienced in his adolescence the daily traumas of the Auschwitz concentration camp. Survival and its relationship of gratitude to Brazil and its identification as Brazilian. His narrative testifies to one of the greatest atrocities suffered by his people during the Shoah in World War II. We try to verify how the exception and the naked life present themselves and dialogue in the narrative reverberating their survival. Nazism no doubt reminds us of the torture and suffering of a people who were penalized, for Auschwitz was not only a concentration camp, it was also a field of forced labor, humiliation, suffering and extermination. From this perspective, we will use Giorgio Agamben ideas based on the state of Exception and nude life as a key reading, concepts considered important for understanding and reflecting on a period in which fundamental rights have been suspended and their memory will always be a challenge, especially when it comes to infants.

Keywords: Testimony. Exception. Memory. Bare life.

\footnotetext{
${ }^{1}$ Possui graduação em Letras - Língua Portuguesa pela Universidade Federal do Pará (2016).

2 Doutor em Teoria e História da Literatura pela UNICAMP. Mestre em Letras - Estudos Literários pela Universidade Federal do Pará (2006). Atualmente é professor Adjunto I da Universidade Federal do Pará - UFPA - Campus de Abaetetuba.
} 


\title{
Para início de conversa
}

\author{
A criança loura \\ Jaz no meio da rua. \\ Tem as tripas de fora \\ E por uma corda sua \\ Um comboio que ignora. \\ A cara está um feixe \\ De sangue e de nada. \\ Luz um pequeno peixe \\ — Dos que bóiam nas banheiras - \\ À beira da estrada. \\ Cai sobre a estrada o escuro. \\ Longe, ainda uma luz doura \\ A criação do futuro... \\ E o da criança loura? \\ Fernando Pessoa
}

Precisamos pensar os embates teóricos presentes no testemunho ao ler um poema como Tomamos a Vila depois de um intenso bombardeamento, de Fernando Pessoa, o qual tomamos como epígrafe deste texto. Da mesma forma que diante da obra, $O$ Sobrevivente: Memória de um brasileiro que escapou de Auschwitz, (2000), escrita por Tova Sender, escriba do testemunho de Aleksander Henryk Laks, sobrevivente dos horrores e atrocidades nazistas durante a segunda guerra mundial. Laks como sobrevivente e testemunha, narra para Sender, a responsável por transformar o testemunho em livro e os horrores que reinavam os guetos e os campos de concentração, evidenciando detalhes de como os judeus foram mortos pelas tropas alemães e como as pessoas eram humilhadas e assassinadas sem ter cometido crime algum, simplesmente por serem judeus. Vejamos, que essa forma de produção do testemunho de Laks com a presença de um escriba, aproxima-se da formulação do testimonio latino-americano, amplamente desenvolvido nos anos sessenta, como destaca Márcio Seligmann-Silva ao diferenciar Zeugnis e Testimonio. Na argumentação do pesquisador vemos certa rigidez entre as formas, ali compreendida como necessária pois a proposta é apresentar um painel diferenciador dessas duas facetas do testemunho, quando o Zeugnis, representa a abordagem em torno do testemunho que faz “uma espécie de 'volta à história' no âmbito do chamado pós-estruturalismo, sob o signo da história como trauma que complexifica a noção do 'fato histórico' e impede sua definição inocente e positivista” (2001, p.122). De outro modo, o Testimonio expressa uma política de memória com "peso muito mais de 
política 'partidária' do que de 'cultural': aqui ocorre a convergência entre política e literatura" (2001, p 125). Em resumo essas duas formulações além de se diferenciarem em seu escopo temático também se diferenciam no campo estrutural. Tentamos abaixo apresentar um quadro resumido das proposições de Seligmann-Silva, correndo o risco de simplificar tais complexas categorias, mas vemo-lo necessário à argumentação:

\begin{tabular}{|l|l|l|}
\cline { 2 - 3 } \multicolumn{1}{c|}{ O evento } & \multicolumn{1}{|c|}{ Zeugnis } & \multicolumn{1}{c|}{ Testimonio } \\
& $\begin{array}{l}\text { Singularidade dos Genocídios } \\
\text { Shoah }\end{array}$ & $\begin{array}{l}\text { Uma contra História } \\
\text { Ditaduras na América Latina } \\
\text { Guerras Decoloniais em África }\end{array}$ \\
\hline A testemunha & $\begin{array}{l}\text { Testis (testemunha secundária) } \\
\text { Superstes (Sobrevivente/Mártir) }\end{array}$ & $\begin{array}{l}\text { Testis (com-provar/certificar) } \\
\text { Herói (necessidade de justiça) } \\
\text { Subalterno (voz necessária) }\end{array}$ \\
\hline O testemunho & $\begin{array}{l}\text { Literalização (intraduzibilidade) } \\
\text { Fragmentação (nós da memória) } \\
\text { Exemplaridade (não-ficção) }\end{array}$ & $\begin{array}{l}\text { Realismo (fidelidade do testemunho) } \\
\text { Oralidade (mediador/compilador) } \\
\text { Exemplaridade (não-ficção) }\end{array}$ \\
\hline A cena & $\begin{array}{l}\text { Tribunal (justiça histórica) } \\
\text { Perlaboração (trauma) } \\
\text { Shoah (recolhimento) } \\
\text { Suspensão voluntária da descrença }\end{array}$ & $\begin{array}{l}\text { Tribunal (citação/uma luta) } \\
\text { Literatura (mito e tragédia) } \\
\text { Restituição da Justiça } \\
\text { Suspensão voluntária da descrença }\end{array}$ \\
\hline A literatura & $\begin{array}{l}\text { Teoria da Memória } \\
\text { Estudos dos genocídios }\end{array}$ & $\begin{array}{l}\text { Literatura (crônica, confissão, diário) } \\
\text { Novela testemunhal }\end{array}$ \\
\hline
\end{tabular}

Quadro 1: Diferenças entre Zeugnis e Testimonio

Vejamos que o quadro não daria conta de assentar o texto de Fernando Pessoa, que destaca um conflito anterior às formulações sobre o testemunho de meados do século XX. Tão pouco, este não seria o objetivo Seligmann-Silva, pois o contexto de Zeugnis, foi provocado por outras expiações. Seu texto nos chama atenção sobre isso quando evoca Adorno e assevera a impossibilidade poética em sua análise sobre Paul Celan, isso porque cada conflito, cada experiência limite possui sua singularidade, o que impossibilita dar conta deles por meio de uma só teorização.

Assim nos perguntamos, como poderíamos enquadrar poemas de quem não foi um narrador nem diretamente testis, nem superstes, mas sim um poeta, como outros, que trazem a cena traumática extremante realista da criança loura morta no meio das ruas, sem futuro, sem esperança, como se fizesse um testimonio, emergido da experiência de uma guerra, mas sem vivê-la. Certamente o poema é um testemunho, uma ficcionalização 
da realidade, possui nele um teor testemunhal, ao mesmo tempo, nele encontramos certa formulação da intraduzibilidade presente em Zeugnis e a formulação de uma política da memória, com suas singularidades, bem diferente das da Shoah, mas com diversos pontos de contato.

De modo similar vemos o testemunho de Aleksander Laks, com um texto essencialmente marcado pelos signos do Zeugnis, em que a singularidade da Shoah transparece na narração de um testemunho superstes e em alguns casos testis, mostra a ecleticidade em seu testemunho, que antes de tudo se apresenta como um testimonio na medida em que em várias passagens procura comprovar, certificar sua narração marcada pela oralidade de um mediador/compilador, como se dá em grande parte do testimonio latino americano.

A guisa de introdução, propomos que a apreensão do testemunho ou de uma literatura de testemunho, se podemos assim chamar, deve articular, em vários casos, não a formulação de uma categorização fixa, mas percebê-las dentro de suas particularidades, este é o caso do testemunho de Laks, que veremos daqui para frente.

\section{Testemunho, sobrevivência e resistência}

As memórias de Laks, como é de praxe em livros de memória, procura traçar sua temporalidade. Começa pelo seu nascimento e a sua primeira infância, para nós esse é um detalhe importante para um livro de testemunho, pois os detalhes que conta não fazem parte de sua memória de sobrevivente, mas sim de um conjunto de narrativas que lhe contaram, já que uma criança não teria como fixar as experiências de seu nascimento o que faz com que o testemunho de Laks inicie de forma, um tanto inusitada quando pensamos nos testemunhos da Shoah, o biografismo ali produzido revela uma narrativa intrigante pois mistura gêneros e intenções diversas. Vejamos uma dessas passagens:

$\mathrm{Na}$ realidade, as circunstâncias do meu nascimento foram bastantes curiosas. Meus pais tiveram um casal de filhos gêmeos, antes de mim. Minha mãe recebeu orientação para não mais engravidar (...). Apesar dessa advertência minha mãe optou por ter um filho. (LAKS \& SENDER, 2014, p. 17)

Nesta passagem temos uma mistura narrativa que passa pela reflexão sobre as histórias de seu nascimento e a necessidade de fomentar as marcas culturais e religiosas 
do judaísmo e das decisões familiares, relacionadas a escolha do nome a particularidades de sua infância, como o fato de ter sido amamentado por ama de leite, até os quatro anos de idade, e não por sua mãe, que falece nessa mesma época, e a necessidade de até os sete anos vestir apenas branco conforme orientou o rabino consultado por seu pai e todas as implicações sociais e traumáticas por ele vivida na infância.

Laks, mais a frente, dedica parte de seu testemunho a nos contar detalhes da vida de sua família buscando sobreviver ao antissemitismo na Polônia e a culpa vivida diante das notícias de perseguição aos judeus alemães e a apatia dos judeus poloneses, vejamos como Laks reflete sobre isso:

A Polônia era um país impregnado de antissemitismo. Havia boicote contra os judeus, limite de vagas nas universidades e proibição de certos cargos públicos (...).

Corria o ano de 1939. Sabíamos que os judeus na Alemanha eram perseguidos. Sabíamos, mas nada fizemos para ajuda-los e nos ajudar. Na verdade, achávamos que não aconteceria conosco. (LAKS \& SENDER, 2014, p. 24)

A culpa não devia estar relacionada à memória infantil, certamente ela se formulou muito tempo depois, na constituição de seu testemunho, já adulto, há formulações que não pertencem ao tempo da narrativa e sim ao tempo da narração, ou seja, são formulações realizadas pela ativação das memória por meio da narração e não fazem parte do momento dos acontecimentos. Esse processo de reflexão vai ser muito presente nos testemunhos da Shoah uma memória reflexiva. Vejamos como isso se dá na passagem a seguir:

Nós, as crianças, costumávamos comentar com orgulho a respeito da cavalaria do exército polonês (...) Para nós, meninos a cavalaria era invencível (...) Éramos ingênuos; não havíamos vivenciado ainda nenhum tipo de violência na nossa curta e feliz infância" (grifos nossos) (LAKS \& SENDER, 2014, p. 25)

No testemunho de Laks nos deparamos com essa dupla visão: ora marcada pelo imaginário heroico sobre a cavalaria, ora pela análise fria sobre o que haveria por vir e como as crianças não tinha como compreender àquela realidade, pois para ele, elas nunca havia sofrido violência, algo impossível, já que ele próprio em outra passagem do testemunho relata o sofrimento em relação às políticas antissemitas e a outras violência sofrida pelos judeus, como no caso de um episódio de greve, quando narra a violência contra os trabalhadores e a consternação que sentiu: "eu fiquei impressionado com o fato, apesar de ser ainda uma criança. Fui para casa sufocado" (LAKS \& SENDER, 2014, p. 
22). Certamente Laks não estava envolvido diretamente na greve, mas ao saber sobre a opressão contra o movimento e a violência sofrida pelos adultos, sentiu-se violentado ao ponto de sufocar. Para ele, a violência psíquica ou simbólica contra o povo judeu não teria como se comparar ao sofrimento vivenciado nos guetos, nas viagens de trem e nos campos de concentração, por isso, entendemos sua reflexão sobre a violência extrema dos campos e do nazismo, essa pode ser escrita com "V" maiúsculo.

É exatamente por isso que Laks considera o ponto de partida do sofrimento de seu povo o $1^{\circ}$ de setembro de 1939 , data em que o exército nazista invade a Polônia. Tornase compreensível este entendimento, pois, daí por diante seu povo trava uma luta diária pela sobrevivência, entretanto, o que transparece é que Laks passará a ter compreensão disso muito tempo depois.

O testemunho de Laks possui particularidades da sua própria relação com sigo, já que muitos anos daquela guerra viveu como criança e adolescente, fazendo com que tenhamos ao longo de seu testemunho passagens ligadas a esse mundo, como os episódios narrados sobre as canções criadas para fazer críticas, pedir esmolas e sobreviver. Vejamos a canção:

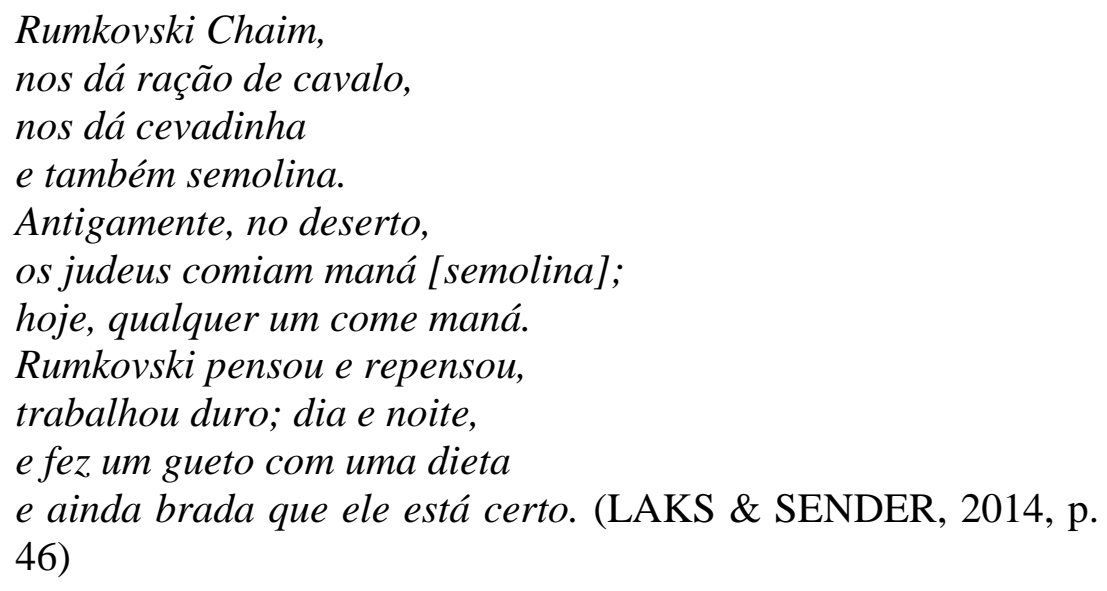

A música, ao mesmo tempo representava uma denúncia contra as ações do presidente polonês, representante naquele momento do foco das críticas dos judeus contra o regime de Hitler, mas sem fazer o confronto contra os alemães, a figura de Rumkovski é expressa sobre o véu do sarcasmo de homem bondoso que brada estar certo. A estratégia de fazer elogios mesclada pela crítica será vista também na canção a seguir:

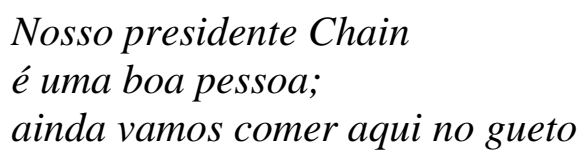


broas com manteiga.

O que podemos fazer com tamanha desgraça,

o que podemos fazer, gente, se temos que comer todos os dias;

se o estômago não quer saber de gueto

e grita e se revolta por comida...

Vendi as cadeiras,

os armários e as camas,

e com tudo isso só consegui

uns poucos bolinhos de cavalo...

O que podemos fazer com tamanha desgraça,

o que podemos fazer, gente, se temos que comer todos os dias;

se o estômago não quer saber de gueto

e grita e se revolta por comida... (LAKS \& SENDER, 2014, p. 47-48)

A relação entre arte e resistência sempre se fez presente, assim como a denúncia das mazelas vividas pela sociedade, vimos isso na poesia de Fernando Pessoa e nas músicas apresentadas no testemunho de Laks, certamente essas músicas representam o grito de liberdade e a necessidade de dias melhores. Muitas vezes encontramos nos testemunhos dos sobreviventes muitas cenas que não estão revestidas de ações de resistência ao regime, mas de formas de garantia de vida, ações isoladas, individuais. Temos no testemunho de Laks uma preocupação maior em nos apresenta como o gueto fazia resistência, enquanto coletivo. As canções, que pela letra, extremamente politizada, estavam nas bocas dos adultos, mas as crianças também faziam suas canções e demarcavam sua resistência, como vemos na canção a seguir:

Nós, crianças, rogamo-lhe,

nosso Deus, criador do mundo:

conceda-nos uma vida delicada e pura

e cultive, em nós, a bondade. (LAKS \& SENDER, 2014, p. 50)

A oração infantil revela a resistência presente também entre os infantes, pois diante de tanto terror e das atrocidades vividas pelos pequenos havia a necessidade de rogar ao Deus judeu a manutenção das virtudes, ao mesmo tempo que expressa todo o desejo de que haja um futuro possível para a existência da bondade e da pureza infantil, que Laks só entendera após a sobrevivência, como vemos na sua reflexão sobre essa época:

Percebo, hoje, quanta grandeza havia nessas palavras e em nossa prece. Vivíamos uma vida precária, arriscada e tolhida. Não tínhamos comida, liberdade, saúde ou casa. Não tínhamos nem mesmo, as condições mínimas de sobrevivência. No entanto, o 
que pedíamos a Deus era pureza e bondade. Perdemos todos os bens materiais, mas não perdemos a dignidade. (LAKS \& SENDER, 2014, p. 51)

O testemunho acima revela também que a compreensão dos acontecimentos vividos por Laks eram nebulosos, pois ser criança naquela experiência limite representava saber e entender menos ainda o que se passava com sigo, com sua família e amigos. Revela que muito do que viveu também fez parte de uma memória que não era sua, mas fazia parte da experiência coletiva de um povo submetido a privações de forma inumana, levando-os a se apegarem ainda mais ao sagrado.

Ao analisar o passado com a experiência do presente na assertiva "Percebo, hoje", nos deparamos com uma formulação particular de testemunho, já que o tempo todo encontramos na narrativa de Laks oscilando entre a memória da infância e a reflexão sobre essa memória, que se constitui como uma memória secundária, de um testemunho arbiter $^{3}$ construída pela audição e arbitragem, pelas histórias contadas à Laks e que ele reproduz como se fossem particulares, suas. E de certo modo as são, porque foram assimiladas como tais, por isso, são memórias de um povo. tomadas e vividas como suas, mas não são só suas, pertencem a uma tradição reflexiva da experiencia concentracionária e traumática, que permanece vivas, em seu presente.

Laks, relata também a experiências de aprendizado no gueto quando criança, quando ficaram marcadas as aulas com o professor de História e Mitologia, posto que a narrar histórias foi a principal atividade daqueles dias e, entre as várias histórias contadas, uma delas tornou-se especial, "Os cem homens de Esparta", pelo fato dessa narrativa representar a força e a resistência coletiva de um povo, vejamos do que se trata a narração:

Se bem me recordo, apesar de tudo que passei nos anos seguintes e dos tantos anos decorridos, o que poderia ter embotado a minha memória, ele relatava sobre as vitórias bélicas de Esparta. Esparta era invencível. Combatia contra todos os Estados gregos e sempre se saía vitoriosa. Até que ocorreu uma batalha contra Atenas, que se teria aliado a outro exército, não sei se Tróia ou um outro, tornando-se mais forte; e Esparta começou a recuar. O exército de Esparta foi sofrendo as baixas, até que chegou ao número de cem soldados. Esses homens decidiram não mais recuar e resistir ao inimigo, bravamente. (LAKS \& SENDER, 2014, pp. 51-52)

\footnotetext{
${ }^{3}$ Essa formulação pode ser melhor compreendida a partir do artigo O testemunho em três vozes: testis, superstes e arbiter. Disponível em: https://periodicos.ufsm.br/LA/article/view/35461/20006
} 
Vemos no testemunho de Laks o quanto resistir era uma necessidade para os judeus, mesmo quando era impossível vencer os opressores. Por isso, os ensinamentos aos infantes eram formulados por meio de tais narrativas. Era necessário plantar a semente da resistência, mesmo em condições tão aviltantes e ensinar às crianças a se esconder, a silenciar, a fugir, pois certamente precisariam desses ensinamentos.

Laks testemunhou o horror e, em vários momentos, precisou se esconder com sua família para que não fossem apanhados pelo exército nazista, mas no momento das aulas não tinha a compreensão exata daqueles ensinamentos, mas abstraiu aquelas narrativas como parte fundamental de sua história. Naquela altura, Laks tinha 12 anos de idade, sua infância, já ia ficando de lado na medida em que começa a ter contato com as primeiras cenas de horror do regime de Hitler, ele lembra: "os nazistas pegavam judeus, enforcavam-nos em postes de luz e deixavam os corpos expostos" (LAKS \& SENDER, 2014, p. 29). A inocência presente em seu olhar míope ${ }^{4}$ vai dando lugar à perplexidade, pois sabia que as pessoas estavam ali, sem ter cometido crime ou delito algum, ou ao menos ter feito resistência às ações do exército nazista "foram executadas para servir de exemplo e evitar qualquer tentativa de reação" (LAKS \& SENDER, 2014, p. 30).

Ainda sobre esse episódio, fica evidente o trauma diante do horror produzido sobre aquela população, pois seu testemunho evidencia uma repetição da sua perplexidade: "infelizmente, não eram bonecos de cera. Eram seres humanos. Eram seres humanos. Eram seres humanos" (Idem).

Quando estudamos a relação ente memória e trauma vemos que é recorrente que os testemunhos estejam marcados por diversas características reveladoras da ferida traumática, que envolve suas narrações. Uma das mais recorrentes é a repetição de sentenças, na passagem anterior vemos que essa repetição revela a necessidade de expressar o nível de perplexidade diante do horror e insensatez diante da crueldade ali expostas.

Posteriormente, Laks nos apresenta detalhes do contorno histórico de sua experiência, narrando como as pessoas eram confinadas no gueto de Lodz e como fez parte das mais de 160 mil pessoas que foram ali enclausuradas, um lugar que na memória

\footnotetext{
${ }^{4}$ Ver: O jogo como estratégia de defesa, sedução e erotismo no cinema latino-americano. Disponível em: http://www.ileel.ufu.br/anaisdosilel/pt/arquivos/silel2011/2769.pdf. Anteriormente pensado por Tânia Sarmento-Pantoja em $O$ olhar da infância em narrativas pós-ditatoriais na América Latina. Anais IX Jornadas Andinas de Literatura Latino Americana - Tomo I, p. 1900-1906.
} 
de Laks ficara fixado pela imagem das cercas de arames farpados, o tratamento desumano, com vivos e mortos, pois "os sepultamentos passaram a valas comuns, onde os corpos eram depositados e cobertos com cal virgem, que evitava o mal cheiro" (LAKS \& SENDER, 2014, p. 43). Em idas e vindas Laks avança em sua narração historiográfica e panorâmica da guerra, descrevendo que o gueto fora somente uma prisão e que muito ainda havia por vir.

Quando os homens de Hitler invadiram a Rússia, uma fagulha de esperança foi acesa. Entre os prisioneiros nascia o desejo de que a derrota alemã poderia estar próxima e, com isso, a liberdade dos judeus. Todavia, esse foi um primeiro dos vários enganos por eles vivenciados. Nesse confronto, a Rússia perdeu para os soldados de Hitler, que passaram a se sentirem mais poderosos ainda, tendo como consequência o início das deportações.

Esse foi um capítulo destinado a expressar como era difícil viver em meio à desinformação e a incerteza, pois ninguém sabia exatamente qual seria o destino dos judeus, ao entrarem naqueles vagões. Laks narra que seu povo era enganado ao ser levados para os trens, a princípio, seriam encaminhados para os campos de concentração, o que já não era bom, mas aos poucos foram descobrindo que a viagem tinha outro destino, cada vez mais dramático e desesperador. Vejamos o testemunho do embarque no trem que levariam ele, seus pais e seus avós:

Fomos conduzidos à estação e Marisin. Lá cada um recebeu um quilo de pão e dez marcos alemães, conforme o prometido. Entramos nos vagões do trem de carga. Minha mãe sugeriu que deixássemos um pouco de pão para mais tarde (...) mas aquele pão que deixamos para comer depois, não comemos mais. Aprendemos uma lição: na guerra, não se deixa nada para depois. (LAKS \& SENDER, 2014, p. 77)

Um aprendizado tortuoso, que os seguiu durante muito tempo, mas a experiência concentracionária dos guetos em nada poderiam se aproximar do sofrimento vivido nas viagens de trens e os campos representaram, para milhares de homens, mulheres, crianças e idosos. Eles foram tratados de forma cruel e sem nenhum tipo de piedade, como bem descreve Laks ao narrar a última vez que viu sua mãe ao chegar no campo de concentração.

Quando chegamos ao campo, após chegarmos ao trem sobre gritos e pancadas, as mulheres foram para um lado e os homem 
para o outro. Meu pai segurava a minha mão com firmeza para não me perder. Havia muito pânico. Não nos despedimos. Vi quando minha mãe me acenou, de longe. Essa foi a última vez que a vi. Nunca mais tive notícia dela. Minha mãe com certeza morreu em Auschwitz. (LAKS \& SENDER, 2011, pp. 82-83)

Nesse momento Laks não é mais criança, mas a luta pela sobrevivência continuará agora apenas com seu pai, vivendo de forma disfarçada, pois os judeus não poderiam saber que eles eram parentes. Dessa maneira, narra as torturas sofridas por ele, seu pai, e outros judeus que ali também se encontravam e para sobreviver, se utilizou de diversas estratégias, pois a cada dia era muito intenso o sofrimento. Foram levados para vários lugares e torturados de varia formas. Um dos momentos mais difíceis testemunhado por Laks foi quando presenciou seu pai chegar ao último estágio, "o mulçumano", após de ter estado semanas na chamada "Marcha da Morte", de mais de 500 quilômetros, entre vários campos de concentração.

O sofrimento foi tão intenso que essas memórias são acompanhadas do trauma, que segundo Gabriela Maldonado e Marta Cardoso é algo que te impossibilita de construir uma nova história. Baseadas em Freud e Seligmann-Silva analisam o trauma como algo que é impossível de esquecer, pois tem sempre algo que traz à tona o evento traumático, podendo ser um cheiro, uma cor, um objeto, algo que relembre esse momento conturbado, como afirma Maldonado \& Cardoso (2009, p. 5):

A noção de memória amnésica nos faz pensar no que SeligmannSilva (2007), em comunicação oral, tratou como "memória de um passado que não passa", conduzindo-nos à ideia de que as marcas deixadas por um evento traumático vêm instalar um presente contínuo. Portanto, estas não se inscrevem como passado, porque não podem ser esquecidas - em função de seu retorno sob a forma de repetição dolorosa. É em razão desta peculiaridade da memória traumática que o autor sustentará, nessa mesma conferência, que "na situação testemunhal o tempo passado é tempo presente".

Podemos observar que o trauma fixa como uma constante na vida da vítima, independentemente do tempo decorrido, por isso, é uma "ferida" que nunca cicatriza, e que se aprende a conviver com ela no tempo presente. $\mathrm{O}$ evento traumático é algo doloroso, pois as marcas e as cicatrizes deixadas tanto no corpo, quanto na alma é aterrorizador como afirma o sobrevivente.

_Tive muitos cortes nos dedos. Até hoje, tenho as marcas das cicatrizes. Em seguida, levei ainda uma coronhada no nariz. Em 
consequência do golpe, fiquei com o nariz quebrado e tenho dificuldade de respirar pelo nariz. Ainda que eu quisesse, não poderia. A cada inspiração lembro-me desse fato, sem conseguir entender esse momento trágico. Porque eles mataram? Por quê? _Tenho muitas marcas. Tenho cicatrizes de todo tipo. Minha alma está cheia delas. Meu corpo também. Minha memória, meu pensamento, meu sono, meus sonhos, meus dias e minhas noites. (LAKS \& SENDER, 2014 p. 111)

Aqui observamos a memória traumática, quando Laks narra o que sofreu nas mãos dos nazistas, deixando evidente as marcas da violência no corpo, na alma e na memória. Por isso, evidencia que não conseguiria esquecer, pois o seu presente é expressão dessas violências. A dificuldade de respirar o impossibilita de esquecer, pois sabe que o nariz quebrado durante a experiência do lager, não foi resultado de algum acidente, por isso esquecer não era uma opção, não conseguiria, pois respira o faz lembra, tornando-se um evento traumático que se atualiza todos os dias.

A condição de sobrevivente, nos leva a compreendê-lo em um estado de exceção, pensado nas formulações de Giorgio Agamben, ao destacar que o papel fundamental do estado de exceção é suspensão dos direitos fundamentais, como o vivido por ele. E que das decisões soberanas nasce à vida nua, vida desqualificada pela suspensão do ordenamento jurídico, que resulta no abuso de poder. Como analisa Agamben:

Se ao soberano, na medida em que decide sobre o estado de exceção, compete em qualquer tempo o poder de decidir qual vida possa ser morta sem que se cometa homicídio, na idade da biopolítica este poder tende a emancipar-se do estado de exceção, transformando-se em poder de decidir sobre o ponto em que a vida cessa de ser politicamente relevante. (AGAMBEN, 2002, p. 149)

Agamben ressalta a condição mulçumana no campo, ao destacar a morte antecipada, sem o homicídio, decidida por um poder que aniquila e soterra qualquer forma de resistência. Dessa forma, o soberano constituía-se de um poder de exclusão-inclusão, de decidir sobre a exceção e regra, sobre a normalidade ou anomia da vida social. Por isso, o soberano decide quem tem o direito de viver ou morrer. Durante a Shoah nos encontramos com diversas narrativas denunciando como as pessoas eram tratadas nos campos, corpos desprovidos de qualquer direito, retirados de sua humanidade, jogados a própria sorte, já que o poder soberano é quem decide qual vida merece ser vivida. Daí 
considerarmos que estamos diante de corpos insacrificáveis, porém matáveis, tais como homo sacer, vejamos a passagem a seguir:

O frio era insuportável, e quase sempre chovia. Alguns pegavam pedaços de papel que embalavam o cimento usado nas obras e enfiavam dentro da roupa para sentir menos frio. Isso era considerado uma transgressão às normas; todo aquele apanhado com papel dentro das roupas tinha o número anotado. À noite, de volta ao campo, éramos contados e, em seguida, tínhamos que presenciar a pancadaria. Os prisioneiros espancados voltavam ao trabalho no dia seguinte. Os sacos de papel que embalavam o cimento iam para o lixo. Para eles, nós valíamos menos que o lixo. (LAKS \& SENDER, 2014 p. 110)

O testemunho de Laks, destaca que para o poder soberano a matabilidade de seus corpos era a regra, pois estavam à mercê de serem espancados, fuzilados ou selecionados para a câmara de gás a qualquer instante. As regras impostas eram insanas, já que elas revelavam como a vida humana não tinha valor, morrer de calor ou frio nos campos de concentração era apenas consequência dada a irrelevância daquelas pessoas para a Gestapo e nada podia ser feito para mudar isso, temos apenas a legitimação da violência, da arbitrariedade e da suspensão dos direitos, gerando o aumentava do poder soberano e a decrepitude dos prisioneiros, que diante das humilhações, da racionalização de comida e da falta de água ficavam cada vez mais magros e doentes, levando-os facilmente ao último estágio, o muselmann,

como era denominado, na linguagem do lager, o prisioneiro que havia abandonado qualquer esperança e que havia sido abandonado pelos companheiros, já não dispunha de um âmbito de conhecimento capaz de lhe permitir discernimento entre o bem e mal, entre nobreza e pobreza e vileza e espiritualidade. Era um cadáver ambulante, um feixe de funções físicas já em agonia. Devemos por mais dolorosa que nos pareça a escolha excluí-lo da nossa consideração (AGAMBEN, 2008, p. 49)

Laks viu seu pai atingir o estágio de completa perda de consciência, aonde o prisioneiro deixava de ter noção das coisas e do mundo, passando a ser considerado um cadáver ambulante, um feixe de funções físicas já em agonia. Seu pai ficou tão magro que não conseguia ter noção de nada, era percebido como um "morto vivo" em decorrência da humilhante condição a qual foi submetido. Vejamos como Laks narra essa passagem:

Meu pai contraiu a doença. Meu pobre pai. Aquele que, além de sofrer por si mesmo, sofria também por mim - e esse talvez fosse 
o drama maior. Ali estava ele padecendo de disenteria. Esvaia-se aos poucos, numa dor que não pode ser descrita. E eu vi isso tudo. Certa vez ele me disse que estava no fim, porque havia expelido os intestinos. Não sei o que é pior: dizer isso ao filho ou ouvir isso do pai. Meu pai tinha entrado em um estado de entrega total. Era estágio anterior à morte, quando as pessoas ficavam totalmente alheias à realidade. Nada mais interessava. A pessoa andava e, em alguns casos, podia até falar, mas não estava mais ligada a este mundo. Era como uma depressão profunda, onde até o extinto de sobrevivência deixava de existir. Não havia mais fome, dor ou medo, era indiferença total. Esse estado era chamado de "mulçumano". E meu pai já estava assim[...] (LAKS \& SENDER, 2014 p. 133)

A experiência com a morte é algo incomparável, principalmente quando se trata de um ente familiar, saber que seu pai estava soterrado, sem condições de resistir, marca a qualquer pessoa, mas quando isso ocorre em um campo de concentração temos uma amplificação dessa experiência. Laks nos apresenta sua reflexão sobre o horror de sobre a certeza da morte de seu pai e reflete sobre o diálogo com seu pai ao revelar sua condição musselmann, pois para ele ouvir de seu pai que chegou ao fundo, tornou-se mais aterrador, por não saber explicar se o pior seria "dizer isso ao filho ou ouvir isso do pai". O efeito de tal experiência, certamente o acompanhou por toda a sua existência.

A entrega total, uma depressão profunda, oriundas de sua condição, mostram que o prisioneiro deveria perder a capacidade de reagir, de indignar-se, de temer, mas não foi o que se passou neste caso, já que a sensatez do pai em chamar o filho para uma conversa final, mostra-nos o quanto era impossível sair do górgona, mas evidencia a preocupação do pai em não abandonar seu filho, mesmo sem condições de resistir.

Meu pai tinha quarenta e quatro anos quando se juntou aos seis milhões de judeus que pereceram no holocausto. Para mim, ele ainda tem essa idade, porque os mortos não envelhecem. Para mim, terá sempre quarenta e quatro anos. Hoje rendo-lhe homenagem fazendo o que ele pediu. Eu conto; conto a nossa história. E cada vez que conto, penso nele. O que mais poderia fazer por meu pai? (LAKS \& SENDER, 2006 134)

Laks sabia da impossibilidade de mudar os acontecimentos naquele momento, entretanto deixa claro que a melhor forma de reverenciar os mortos da Shoah é por meio do testemunhando. Narrar é a única maneira que o sobrevivente encontra para dar conta 
de suas memórias, de provar para si mesmo que ainda está vivo e que tudo o que viveram nos campos de concentração não se repita.

\section{Outras considerações}

A Shoah, a maior catástrofe do século XX, deve ser melhor conhecida e estudada, não só por críticos da filosofia, da história ou da sociologia, deveria compreendido por todo tipo de pessoa, sem distinção de cor, credo ou raça, por isso é importante a leitura de O sobrevivente: memórias de um brasileiro que escapou de Auschwitz, testemunho de um sobrevivente dos campos de concentração, que migrou para o Brasil e por conta do acolhimento que recebeu, passou a se sentir brasileiro.

A narrativa de Laks potencializa compreender que precisamos combater o autoritarismo, posto que é por meio dele que o poder soberano se instala, e revela como seres humanos podem chegar à níveis tão baixos de crueldade, confinando grupos sociais em guetos, com fome e sofrendo bárbaras torturas físicas e psicológicas. Laks em seu livro narrar, não só sua história, mas a sobrevivência de um povo e de sua cultura em um período em que as liberdades individuais eram retiradas por conta do totalitarismo moderno, que parece não ter ficado confinado ao século passado.

\section{Referências:}

AGAMBEN, Giorgio. O que resta de Auschwitz: o arquivo e a testemunha. (Homo Sacer III). Tradução Silvino J. Assmann. São Paulo: Boitempo, 2008.

AGAMBEN, Giorgio. Homo sacer: o poder soberano e a vida nua (zoé) I. Trad. Henrique Burigo. Belo Horizonte: Editora UFMG, 2012.

LAKS, Aleksander Henrik \& SENDER, Tova. O Sobrevivente: Memórias de um Brasileiro de escapou de Auschwitz. Rio de Janeiro: Record, 2014.

MALDONADO, Gabriela; CARDOSO, Marta Resende. O trauma psíquico e o paradoxo das narrativas possíveis, mas necessárias. Pisc. Clin. Rio de Janeiro, vol..21 n. 1, p. 4557, 2009. 
PESSOA, Fernando. O Cancioneiro. 2018, p 46. Disponível em: http://www.dominiopublico.gov.br/download/texto/pe000006.pdf. Acesso em 20/02/2018.

SELIGMANN-SILVA, Marcio. Zeugnis e Testemonio: um caso de intraduzibilidade entre conceitos. Revista Letras. $\mathrm{N}^{\circ}$ 22. Jun, 2001. Disponível em http:// w3. ufsm.br/revistaletras/artigos_r22/ 11_marcio_silva.pdf. Acesso em 20/08/2009. 